\title{
TEORIA DA RELEVÂNCIA E ANÁLISE SOCIORRETÓRICA DE GÊNEROS TEXTUAIS: ANÁLISE DE CORRELAÇÕES ENTRE CHAMADAS DE CAPA E RESPECTIVOS TEXTOS CHAMADOS
}

\author{
RELEVANCE THEORY AND SOCIO-RHETORICAL \\ ANALYSIS OF GENRES: ANALYSIS OFCORRELATIONS BETWEEN HEADLINES AND HEADLINED TEXTS \\ TEORÍA DE LA RELEVANCIA Y ANÁLISIS SOCIORRETÓRICO DE GÉNEROS TEXTUALES: ANÁLISIS DE
CORRELACCIONES ENTRE LLAMADAS DE PORTADA Y RESPECTIVOS TEXTOS LLAMADOS
}

\author{
Fábio José Rauen* \\ Universidade do Sul de Santa Catarina - UNISUL, Tubarão, BR
}

\begin{abstract}
RESUMO: Este estudo pertence ao Projeto "Teoria da relevância e análise sociorretórica de gêneros textuais", cujo objetivo é analisar interfaces teóricas e conceptuais dessas duas linhas de pesquisa a partir de corpora de gêneros jornalísticos. Neste artigo, avaliam-se as correlações entre chamadas de capa e o conjunto lead e texto chamado, argumentando que os estímulos ostensivos da chamada de capa e do lead do texto chamado formam um todo com o corpo principal do texto chamado no qual os primeiros funcionam como elementos direcionadores da escala focal do último. Para dar conta dessa hipótese, destacou-se a chamada de capa 27 e respectivo texto chamado 33 de Caldeira (2007, p. 77 e 114) sobre a proibição de publicidade externa na cidade de São Paulo, coletada da edição de 27 de setembro de 2006 de Folha de S. Paulo.

PALAVRAS-CHAVE: pragmática cognitiva; teoria da relevância; teoria sócio-retórica; gêneros textuais; chamada de capa.
\end{abstract}

ABSTRACT: This study is part of the Project entitled "Relevance Theory and Socio-Rhetorical Genre Analysis," which aims to analyze the theoretical and conceptual interfaces of these approaches based on journalistic genre corpora. In this paper, we evaluate the correlations between front-page texts and inner texts, arguing that ostensive stimuli of both front-page and inner text headlines and leads form a whole with the inner text itself.The former texts guide the focal scale elements of the latter ones. In order to deal with this hypothesis, we highlighted the 27th front-page text, and the 33rd inner text of Caldeira (2007, p. 77 and 114) on the prohibition of outdoor advertising in São Paulo, collected from September 27, 2006 edition of Folha de S. Paulo. KEYWORDS: cognitive pragmatics; relevance theory; socio-rhetorical theory; genre; front-page text.

RESUMEN: Este estudio pertenece al Proyecto “Teoría de la relevancia y análisis sociorretórico de géneros textuales”, cuyo objetivo es analizar interfaces teóricas y conceptuales de esas dos líneas de investigación a partir de corpora de géneros periodísticos. En este artículo, se evalúan las correlaciones entre llamadas de portada y el conjunto lead y texto de llamada, argumentando que los estímulos ostensivos de la llamada de portada y del lead del texto chamado forman un todo con el cuerpo principal del texto de llamada en que los primeros funcionan como elementos que dirigen la escala focal del último. Para dar cuenta de esa hipótesis, se destacó la llamada de portada 27 y el respectivo texto de llamada 33 de Caldeira (2007, p. 77 y 114) sobre la prohibición de publicidad externa en la ciudad de São Paulo, recolectada de la edición de 27 de septiembre de 2006 de la Folha de S. Paulo.

PALABRAS-CLAVE: pragmática cognitiva; teoría de la relevancia; teoría sociorretórico; géneros textuales; llamada de portada.

\section{NOTA INTRODUTÓRIA}

O presente estudo pertence ao projeto Teoria da relevância e análise sociorretórica de gêneros textuais do Programa de Pós-Graduação em Ciências da Linguagem da Universidade do Sul de Santa Catarina (Unisul), que visa analisar interfaces teóricas e conceptuais dessas duas vertentes de pesquisa com base em corpora de gêneros jornalísticos. O projeto iniciou-se com a análise de cartas-consulta diretas e indiretas, cujos resultados permitiram depreender não somente as interfaces entre relevância e organização retórica, mas também refinar o próprio conceito desse gênero e de seus dois subtipos (RAUEN, 2007, 2009, 2010).

Nesta fase do projeto, pretende-se analisar as correlações entre 31 chamadas de capa e 38 textos desenvolvidos por elas chamados, que foram selecionados dos jornais Folha de S. Paulo (São Paulo, SP), Diário Catarinense (Florianópolis, SC) e A Tribuna (Araranguá, SC) na dissertação de Caldeira (2007). O estudo de Caldeira, baseado em Bonini (2004a), Swales (1990), Bathia (1993) e Biber (1988), visou determinar não somente a organização retórica das chamadas de capa, mas também examinar relações estruturais e de conteúdo entre esses textos. 
No que se refere à chamada de capa, Caldeira (2007, p. 6) verificou quatro movimentos: caracterizar o texto, apontar um tema, especificar o tema e direcionar o leitor a páginas internas do jornal. No que se refere às correlações, o autor verificou que: os textos chamados constituíam-se de notícias e reportagens; as chamadas, em geral, remetiam a um único texto; as informações das chamadas remetiam a diversas partes do texto chamado sem se configurar como um resumo desse texto; e os processos de paráfrase prevaleciam sobre os processos de cópia na configuração das chamadas.

Este artigo apresenta os primeiros resultados de uma revisitação desse corpus a partir do aparato analítico cognitivo-pragmático guiado pelos princípios cognitivo e comunicativo de relevância de Sperber e Wilson (1986, 1995). ${ }^{1}$ A hipótese a ser desenvolvida aqui é a de que os estímulos ostensivos do título e do lead da chamada de capa e do texto chamado formam um todo com o corpo principal do texto chamado no qual os primeiros funcionam como elementos direcionadores da escala focal do último.

Para ilustrar essa hipótese, destacou-se a chamada de capa 27 de Caldeira (2007, p. 77) sobre a proibição de publicidade externa na cidade de São Paulo, coletada da edição de 27 de setembro de 2006 de Folha de $S$. Paulo e analisada em termos de movimentos e passos retóricos pelo autor como segue:

\begin{tabular}{|c|c|c|}
\hline Movimentos & Texto & Passos \\
\hline $\begin{array}{l}\text { I - Caracterizar o } \\
\text { texto }\end{array}$ & (1) Câmara de SP aprova proibição de outdoor & $\begin{array}{l}\text { (I-1B) Intitular } \\
\text { o texto mediante } \\
\text { informação } \\
\text { central }\end{array}$ \\
\hline $\begin{array}{l}\text { II - Apontar um } \\
\text { tema }\end{array}$ & $\begin{array}{l}\text { (2) A Câmara de São Paulo aprovou texto vetando a } \\
\text { publicidade externa, como outdoors, faixas, banners e } \\
\text { até anúncios em táxis e bicicletas. }\end{array}$ & $\begin{array}{l}\text { (II) Apontar um } \\
\text { tema }\end{array}$ \\
\hline $\begin{array}{l}\text { III - Especificar o } \\
\text { tema }\end{array}$ & $\begin{array}{l}\text { (3) O prefeito Gilberto Kassab (PFL), autor do projeto } \\
\text { original, vai sancionar a lei. (4) Os vereadores } \\
\text { ampliaram as proibições, vetando anúncios em aviões, } \\
\text { por exemplo. } \\
\text { (5) A Câmara estendeu para } 31 \text { de dezembro o prazo } \\
\text { para retirada da propaganda existente, que era de } 30 \\
\text { dias. } \\
\text { (6) Os vereadores também revogaram lei que permitia, } \\
\text { por licitação, passar à iniciativa privada a venda de } \\
\text { anúncios no mobiliário urbano. (7) Kassab terá de } \\
\text { enviar novo projeto sobre o assunto. }\end{array}$ & $\begin{array}{l}\text { (III-4) Listar } \\
\text { fatos } \\
\text { relacionados }\end{array}$ \\
\hline $\begin{array}{l}\text { IV - Direcionar a } \\
\text { páginas internas } \\
\text { do jornal }\end{array}$ & (8) Pág. C1 & $\begin{array}{l}\text { (IV) Direcionar } \\
\text { a páginas } \\
\text { internas do } \\
\text { jornal }\end{array}$ \\
\hline
\end{tabular}

Quadro 1 - Movimentos e passos retóricos da chamada de capa 27 coletada da edição de 27 de setembro de 2006 de Folha de S. Paulo por Caldeira (2007).

Fonte: Caldeira (2007, p. 77).

Essa chamada de capa correlaciona-se com o texto chamado 33 (CALDEIRA, 2007, p. 114), transcrito a seguir:

(1) Câmara proíbe outdoors em São Paulo

(2) Nova lei também veta anúncios em ônibus, táxis e até em aviões; empresas têm até o fim do ano para retirar a propaganda.

(3) Multa para quem desobedecer a norma será de, no mínimo, $\mathrm{R} \$ 10$ mil; prefeito Kassab promete fiscalização "rigorosa".

(4) EVANDRO SPINELLI

\footnotetext{
${ }^{1}$ Texto provisório da presente pesquisa foi publicado no VI Simpósio Internacional de Estudos de Gêneros Textuais - SIGET (RAUEN, 2011). Este artigo incorpora melhorias decorrentes das discussões do Evento.
} 


\section{(5) JOSÉ ERNESTO CREDENDIO}

\section{(6) DA REPORTAGEM LOCAL}

(7) A Câmara de São Paulo aprovou ontem uma lei que acaba com a propaganda externa na cidade. (8) A partir de $1^{\circ}$ de janeiro ficam proibidos painéis eletrônicos, outdoors, faixas e banners. (9) Todo comércio e serviços, incluindo bancos, terá que reduzir as placas nas fachadas.

(10) O prefeito Gilberto Kassab (PFL) sancionou ontem mesmo o projeto. (11) "A lei foi aprovada para valer, e a fiscalização será mais rigorosa ainda”, disse. (12) Segundo ele, serão criadas equipes especiais para retirar anúncios irregulares. (13) A multa mínima para quem descumprir a lei será de $\mathrm{R} \$ 10$ mil.

(14) Mesmo sob protestos e contra o lobby das empresas de publicidade exterior, setor que movimenta $\mathrm{R} \$ 200$ milhões ao ano na cidade, Kassab obteve uma vitória expressiva - foram 45 votos a 1. (15) "Em pouco tempo, poderemos sonhar com uma diminuição radical da poluição visual”, declarou o prefeito.

(16) Além da propaganda em placas, também estarão proibidas a publicidade em táxis, a distribuição de panfletos em vias públicas e até a veiculação de anúncios em dirigíveis e aviões.

(17) O que continuará valendo provisoriamente em 2007, mas apenas até o vencimento dos contratos, serão as propagandas em ônibus e no mobiliário urbano (bancas, pontos de ônibus, lixeiras, relógios etc.).

(18) O mercado publicitário reagiu, fala em ameaça a cerca de 20 mil empregos e já preparou pareceres jurídicos para entrar na Justiça contra a prefeitura. (19) A Associação Comercial de São Paulo considera a lei de difícil aplicação e também prevê uma corrida à Justiça.

(20) O texto original, de autoria do prefeito, foi alterado por um acordo entre os líderes dos partidos e ficou ainda mais restritivo. (21) Diminuiu, por exemplo, o tamanho máximo de placas em fachadas de até $10 \mathrm{~m}$ - que passou de $4 \mathrm{~m} 2$ para $1,5 \mathrm{~m} 2$.

(22) Por outro lado, o projeto de Kassab previa somente 30 dias para a lei entrar em vigor, prazo estendido para até o fim do ano, e ainda permite que a prefeitura conceda mais 90 dias, caso o proprietário do anúncio prove que não conseguiu retirá-lo por algum motivo.

(23) Na mesma sessão, os vereadores revogaram uma outra lei que permitia à prefeitura licitar a propaganda no mobiliário urbano. (24) Kassab terá que enviar novo projeto e negociar para conseguir privatizar a exploração do espaço público.

(25) O único voto contrário ao projeto foi do vereador Dalton Silvano (PSDB), ligado à área de publicidade. (26) "Quem perdeu foi a cidade de São Paulo. (27) Uma cidade sem publicidade é uma cidade fria”, disse.

Para dar conta dessa demanda, este artigo foi dividido em mais quatro seções. Na segunda seção, fazem-se breves anotações sobre a Teoria da Relevância. Na terceira seção, analisa-se o texto da chamada de capa com ênfase na noção de escala focal. Na quarta seção, cotejam-se os dois textos em questão. E, na quinta seção, apresentam-se as considerações finais.

\section{BREVES ANOTAÇÕES SOBRE A TEORIA DA RELEVÂNCIA}

A Teoria da Relevância é uma abordagem pragmático-cognitiva fundamentada em dois princípios: o princípio cognitivo de que a mente humana está engrenada para maximizar a relevância, e o princípio comunicativo de que todo ato de comunicação ostensiva gera expectativas precisas de relevância.

A noção de relevância consiste no resultado do cotejo entre os produtos cognitivos derivados do processamento de inputs direcionados à cognição humana (enunciados, pensamentos, memórias, percepções sensoriais, entre outros), chamados de efeitos cognitivos, e o gasto energético necessário para processá-los, chamado de esforço de processamento. Um input será relevante quando ele produzir efeitos cognitivos que superem o esforço cognitivo necessário para processá-lo. 
Considerando-se o processamento da linguagem natural, os inputs são denominados estímulos ostensivos, visto que são pistas abertas e intencionalmente pretendidas como relevantes pelos falantes/escritores. $\mathrm{O}$ processamento de um estímulo ostensivo por um indivíduo, dentro de um contexto de suposições cognitivas a ele disponíveis, pode gerar algum efeito cognitivo, modificando ou reorganizando suas suposições prévias. Esse estímulo pode fornecer evidências que fortalecem as suposições existentes, contradizem ou enfraquecem as suposições existentes ou que derivam implicações contextuais que constituem informações novas, ou seja, conclusões que são fruto da combinação do input com o contexto cognitivo e que não resultam do input ou do contexto isoladamente.

Tome-se, por exemplo, o título da chamada de capa.

(1) Câmara de SP aprova proibição de outdoor.

Esse enunciado funciona como um estímulo ostensivo, porque foi pretendido intencionalmente para transmitir uma intenção informativa. Imagine-se um leitor que estivesse acompanhando o tema da proibição dos outdoors e que, entre suas suposições prévias, houvesse uma suspeita (2) de que essa medida seria aprovada:

(2) A Câmara de São Paulo provavelmente aprovará a proibição de outdoors.

Nesse caso, o enunciado (1) funcionaria como confirmação dessa suspeita e obteria sua relevância ao modificar o grau de força da suposição de provável para certa, fortalecendo-a. Por outro lado, imagine-se um leitor cético que suspeitasse que essa medida não seria aprovada:

(3) A Câmara de São Paulo provavelmente não aprovará a proibição de outdoors.

Agora, o enunciado (1) fornece uma informação que contradiz essa suspeita e obtém sua relevância por enfraquecê-la. Por fim, imagine-se um leitor que tem um outdoor na fachada de sua residência.

(4) Eu tenho um outdoor na fachada de minha residência.

Nesse último caso, a informação do enunciado (1) combinaria com essa suposição e geraria a inferência (5) de que o leitor deve retirar o outdoor.

(5) Eu tenho de retirar o outdoor da fachada de minha residência.

Sperber e Wilson $(1986,1995)$ argumentam que, em iguais condições, quanto maiores são os efeitos cognitivos derivados do processamento de um estímulo ostensivo, maior será a relevância desse estímulo no contexto prévio de suposições de um indivíduo. Todavia, na medida em que gerar efeitos contextuais implica investir energia cognitiva, os autores propõem que, em iguais condições, sendo menor o esforço de processamento, maior será a relevância.

Por hipótese, em idênticas condições contextuais, o enunciado (1a) será mais relevante que o enunciado (1b) que contém uma dupla negação lógica:

(1a) Câmara de SP aprova proibição de outdoor.

(1b) Câmara de SP não aprova a não proibição de outdoor.

Segundo o que versa o princípio cognitivo de relevância, os recursos cognitivos são direcionados para as informações que parecem mais relevantes ao indivíduo; segundo o que prevê o princípio comunicativo de relevância, um falante/escritor gera uma expectativa de relevância ótima pelo simples ato de dirigir-se a um ouvinte/leitor. Dessa forma, afirma-se que um enunciado é otimamente relevante quando: a) ele é suficientemente relevante para merecer ser processado por um indivíduo e b) ele é o estímulo mais relevante que o falante/escritor se dispôs ou foi capaz de produzir, graças às suas preferências ou habilidades.

Visto que o ouvinte/leitor pretende alcançar uma interpretação que satisfaça sua expectativa de relevância ótima, ele precisa enriquecer esses estímulos ostensivos linguisticamente codificados, através de processos inferenciais pragmáticos, para obter um significado explícito e, muitas vezes, obter um significado implícito 
com base nesse significado explícito, sempre seguindo uma rota de esforço mínimo e sempre terminando o processo quando a interpretação obtida se conforma com sua expectativa de relevância. É precisamente isso o que prediz o processo teórico de compreensão guiado pela noção de relevância.

Processo teórico da compreensão com base na relevância.

Seguir um caminho de esforço mínimo na computação de efeitos cognitivos:

a) considerar hipóteses interpretativas (desambiguações, atribuições de referência, suposições contextuais, implicaturas, etc.) seguindo a ordem de acessibilidade;

b) parar quando é alcançado o nível esperado de relevância. (WILSON, 2005, lição 4, p. 7, tradução própria).

Nesse processo, a forma linguística do enunciado é encaixada dentro de uma forma lógica. Geralmente, essa forma lógica ainda não se constitui como uma forma proposicional e precisa ser enriquecida pragmaticamente com base em dados contextuais. Esse processo de enriquecimento gera uma explicatura. No caso de uma implicação contextual, a explicatura atua como premissa implicada a partir da qual é possível gerar dedutivamente uma conclusão implicada ou implicatura.

Vale mencionar que Sperber e Wilson $(1986,1995)$ propõem a operação de um mecanismo ou módulo dedutivo nesse processo interpretativo. Esse mecanismo toma como input certo conjunto de suposições e deduz todas as conclusões possíveis desse conjunto, operando de modo não trivial (sensível à força das suposições) e não demonstrativo (ou seja, passível de ser confirmado, mas não de ser provado).

Retome-se a implicação de que a proibição dos outdoors implica a retirada do outdoor da frente da casa do leitor. Nesse caso, o primeiro passo é o processamento do título (1) da chamada de capa.

Para dar conta da análise desse enunciado, ele foi descrito em quatro versões. Na versão (1a), apresentam-se seus elementos linguísticos; na versão (1b), descreve-se a forma lógica subjacente ${ }^{3}$; na versão (1c), apresentam-se os preenchimentos das entradas lógicas, de modo a compor a explicatura; e, na versão (1d), encaixa-se a explicatura numa descrição que engloba o ato de fala ${ }^{4}$.

(1a) Câmara de SP aprova proibição de outdoor.

(1b) (aprovar x, y, $\alpha_{\text {lugar }}, \beta_{\text {tempo). }}$.

(1c) Câmara [DE VERADORES DO MUNICÍPIO] de SP [SÃO PAULO] aprova [UMA LEI DE] proibição de outdoor $\varnothing$ [NO MUNICÍPIO DE SÃO PAULO $\varnothing$ [NUM TEMPO QUE SUCEDE A APROVAÇÃO DA PROIBIÇÃO].

(1d) ALGUM JORNALISTA DO JORNAL FOLHA DE S. PAULO AFIRMA NA CHAMADA DE CAPA DO JORNAL FOLHA DE $S$. PAUlo QUE A CÂMARA DE VEREADORES DO MUNICÍPIO DE SÃo PAUlo APROVA UMA LEI DE PROIBIÇÃO DE OUTDOOR NO MUNICÍPIO DE SÃO PAULO NUM TEMPO QUE SUCEDE A APROVAÇÃO DA PROIBIÇÃO.

A descrição (1d) captura a ideia de que alguémi [um jornalista do jornal folha de s. pauloi] afirma algo $P$ no $\operatorname{lugar}_{j}$ [na chamada de capa do jornal folha de s. pauloj], tal que $P$ significa que alguém $k$ [a câmara de vereadores do município de são paulo $\mathrm{k}_{\mathrm{k}}$ ] aprovou algol [uma lei de proibição de outdoor ${ }_{1}$ em algum lugar $\mathrm{m}_{\mathrm{m}}$ [no município de são paulom] e em algum tempon [aquele que sucede a aprovação da proibiçãon].

\footnotetext{
$2 \mathrm{O}$ mecanismo opera apenas por regras lógicas de eliminação do tipo eliminação-e, modus ponens e modus tollens. Na regra de modus ponens, por exemplo, se há uma relação de implicação entre duas suposições P e Q, quando a primeira é afirmada P, segue-se necessariamente a segunda Q. Formalmente: "P $\rightarrow \mathrm{Q}, \mathrm{P}, \mathrm{Q}$ " (o símbolo $\rightarrow$ equivale à operação lógica de implicação, se P então Q). Por vezes, é possível combinar as duas regras como é o caso da regra de modus ponens conjuntivo: " $(P \wedge Q) \rightarrow R, P \rightarrow R, R$ ” ou então " $(P \wedge Q) \rightarrow R, Q \rightarrow R, R$ ".

3 Como certas circunstâncias são essenciais para a interpretação relevante, elas serão consideradas e indexadas por letras gregas na descrição da forma lógica.

4. Considera-se a seguinte convenção na descrição dos estímulos: os enunciados ou partes de enunciados retomados são apresentados entre aspas duplas: "aprova proibição de outdoor"; as expressões linguísticas, quando referenciadas, são apresentadas entre aspas simples: 'câmara'; as entradas enciclopédicas são apresentadas em versalete: câmara; e as referências no mundo, quando pertinentes, são apresentadas sem qualquer indicativo: câmara.
} 
Com base nessa descrição, pode-se revisitar a inferência feita pelo leitor ${ }^{5}$.

$\mathrm{S}_{1}$ - Algum jornalista do Jornal Folha de S. Paulo afirma na chamada de capa do Jornal Folha de S. Paulo que a Câmara de Vereadores do município de São Paulo aprovou a proibição de outdoor no município de São Paulo num tempo que sucede a aprovação da proibição (premissa implicada que decorre da explicatura do enunciado (1) da chamada de capa);

$\mathrm{S}_{2}$ - O leitor tem um outdoor na fachada da residência do leitor (premissa implicada que decorre de uma suposição factual recuperada da memória enciclopédica do leitor);

$\mathrm{S}_{3}-\mathrm{S}_{1} \wedge \mathrm{S}_{2} \rightarrow \mathrm{S}_{4}($ dedução por modus ponens conjuntivo);

$\mathrm{S}_{4}-\mathrm{O}$ leitor tem de retirar o outdoor da fachada da residência do leitor (conclusão implicada).

No caso, o leitor, tendo considerada como verdadeiras as duas premissas implicadas, gera a conclusão implicada de que deve retirar o outdoor da fachada de sua residência.

Conhecido em linhas muito gerais o aparato descritivo da Teoria da Relevância, analisa-se na seção seguinte a chamada de capa como base na noção de escala focal.

\section{A CHAMADA DE CAPA E A ESCALA FOCAL}

Antes de falar sobre as chamadas de capa, vale mencionar o papel da capa nos jornais. Uma empresa jornalística capitalista ocidental é uma indústria que faz das notícias uma mercadoria, do público um mercado e do leitor um consumidor. Logo, a primeira página do jornal deve funcionar como "uma espécie de vitrine do produto editorial" (SIQUEIRA, 2006), ou seja, o local onde jornal vende a si mesmo (RIBEIRO apud FERREIRA JÚNIOR, 2003, p. 72).

Bonini (2003b) defende que a chamada serve como elemento de excitação para a compra do exemplar e não apenas como um indexador do conteúdo do jornal. Para esse autor (2003a) as chamadas de capa configuram-se como um daqueles gêneros que estruturam o jornal, por ele definidos como gêneros centrais presos.

O Manual de Redação e Estilo de $O$ Globo afirma que a chamada é dos mais importantes textos do jornal.

O seu conjunto é a vitrine de cada edição e tem os maiores índices de leitura. A chamada precisa ao mesmo tempo atrair a atenção do leitor para as páginas internas e constituir informação completa em si. Valem para ela os princípios que regem a redação de leads e também - com ênfase maior, se isso é possível - a norma sobre promessas: é desmoralizante para o jornal que o leitor se decepcione com uma notícia interna que oferece menos do que a chamada promete. (1998, p. 57, grifo no original).

No Manual Geral de Redação da Folha de S. Paulo (1984), por chamada de primeira página define-se um texto que apresenta a notícia ao leitor. Uma chamada deve sintetizar e conter as informações mais importantes da notícia. Ela deve conter frases curtas, sugerindo rapidez quase telegráfica e remetendo obrigatoriamente à página onde está o texto que ela resume. Uma chamada de capa "geralmente aborda apenas um assunto, mas, nos textos de manchetes, por exemplo, pode abrigar, em parágrafos diversos, vários assuntos referentes ao mesmo tema" (p. 22).

Conforme síntese de Caldeira (2007, p. 33), as chamadas: localizam-se na primeira página dos jornais ou de seus cadernos; remetem o leitor a páginas internas que contêm a notícia ou reportagem completa; são constituídas, geralmente, por um título e a síntese (resumo) de um texto interno; operam como vitrine da edição, de modo a promover a compra do exemplar e a sua leitura; e são constituídas de frases curtas, claras e objetivas.

5 Nessa inferência, usou-se a seguinte convenção: por S1-4, descrevem-se as suposições mentais supostamente construídas pelo leitor; entre parênteses, descrevem-se as origens dessas suposições; e pela fórmula $\mathrm{S} 1 \wedge \mathrm{S} 2 \rightarrow \mathrm{S} 4$, descreve-se o cálculo dedutivo subjacente à passagem das premissas implicadas para a conclusão implicada. 
Considerados esses apontamentos sobre o gênero, argumenta-se neste artigo que, do ponto de vista cognitivo, os jornalistas têm dois objetivos ao produzir uma chamada de capa: gerar certa modificação no ambiente cognitivo do leitor, de modo a motivá-lo a comprar o jornal ou a ler o texto chamado; e, como consequência do primeiro objetivo, gerar um texto que reduza o custo de processamento dessa modificação.

Uma vez que os enunciados são processados passo o passo, por hipótese, o leitor acessa alguns de seus constituintes, com suas entradas lógicas e enciclopédicas associadas, antes de outros. Segundo Sperber e Wilson (1986, 1995), explorar de modo eficiente essa sequência temporal é essencial para ampliar a relevância. Quanto mais cedo for obtida a desambiguação e forem atribuídas as referências de itens lexicais, menor será o esforço de processamento. Inversamente, um maior número de interpretações possíveis a que o leitor tenha de estar atento ao processar o enunciado, ampliará o esforço de processamento requisitado, diminuindo a relevância.

Se isso estiver correto, é de se esperar que os jornalistas, objetivando relevância ótima, formulem seu enunciado para facilitar o processamento do leitor. Contudo, há de se considerar que se impõem constrições próprias do fazer jornalístico, como aquelas relacionadas à equação de tempo e de espaço, ambos nem sempre ideais. Posto isso, é de se esperar que o desempenho dos jornalistas seja compatível nem tanto com suas preferências, mas principalmente com suas habilidades de contornar essas constrições.

Retome-se o título (1) da chamada em estudo. Para Erbolato (1991), um título de chamada de capa é um resumo da matéria, destacando seu aspecto principal ou mais sugestivo. Um título deve ser trabalhado de tal forma a deixar o leitor interessado em ler o texto. Para ele, deve haver sempre um verbo explícito ou implícito num título e, por meio desse verbo, deve-se obter o reflexo do tom da matéria. Para Douglas (apud MELO, 1994), o título, além de sua função técnica, anunciar a notícia e resumir seu conteúdo, e estética, tornar o jornal atraente, tem um potencial de orientação ao indicar a importância de uma notícia.

Em tese, para interpretar o enunciado (1), os leitores do jornal formam hipóteses antecipatórias sobre sua estrutura lógica e resolvem ambiguidades e ambivalências baseadas nessas hipóteses. Na sentença, hipóteses antecipatórias a serem confirmadas relacionam-se entre si logicamente, de modo que uma hipótese é implicada pela outra, formando uma escala focal em que "cada membro implica analiticamente o membro que se encontra na posição anterior e é analiticamente implicado pelo membro que vem logo a seguir" (SPERBER; WILSON, 1995, p. 208). Assim, numa comunicação bem sucedida, o leitor vê confirmadas suas hipóteses antecipatórias lançadas durante o processo de interpretação do enunciado.

Para uma demonstração muito simplificada, observe-se que a sentença (1a), que representa o título da chamada, pode ter uma estrutura subjacente em árvore (1b) e a sua forma lógica uma estrutura (1c).

(1b)

(1a) Câmara de SP aprova proibição de outdoor. $\mathrm{S}$

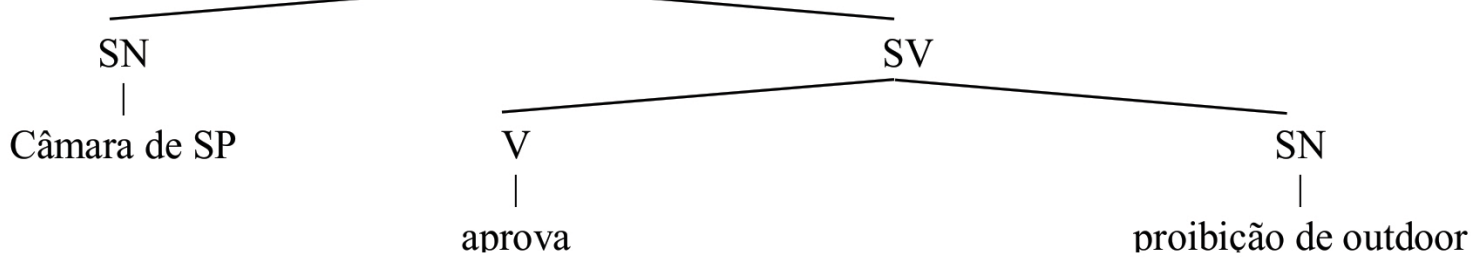

(1c)

algo é o caso

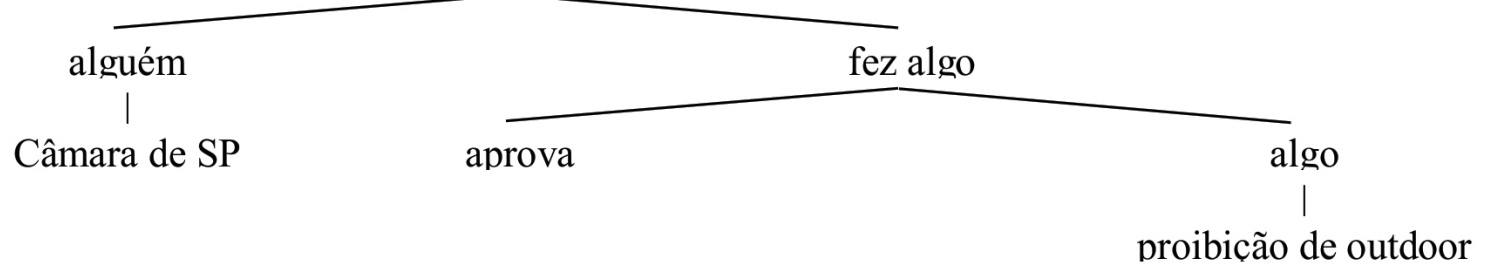

Desse modo, uma representação proposicional de que "a Câmara de SP aprovou a proibição de outdoor" transmitiria, por meio das etiquetas dos nós de seu diagrama em árvore, a informação de que "alguém fez 
algo", "a Câmara de SP fez algo", "a Câmara de SP aprovou algo" e "a Câmara de SP aprovou a proibição de outdoor". Assim, se o leitor antecipa que um verbo transitivo como 'aprovar' é seguido por um SN, ele poderá fazer a hipótese antecipatória de que alguém aprovou algo, e esse tipo de hipótese deve contribuir, obviamente, para a desambiguação e atribuição de referências.

Mesmo no domínio do SN 'Câmara de SP', por exemplo, o item lexical 'câmara' pode gerar a hipótese de que é uma câmara de algum órgão, mas não necessariamente uma câmara de vereadores e muito menos de vereadores paulistanos. O jornalista confia que a primeira interpretação acessível é a de que se trata de uma câmara de vereadores, mas não deixa implícito o município, mesmo sendo a Folha de S. Paulo um jornal paulistano. Por hipótese, deixar o município implícito nesse caso gera um aumento de custo injustificável.

O item lexical 'aprova', por sua vez, tem de ser considerado agora no contexto da interpretação implícita de que se trata de uma câmara de vereadores. Para isso, o leitor tem de contribuir com a suposição factual de que 'câmaras de vereadores aprovam leis'. Repare-se, contudo, que câmaras de vereadores não somente fazem isso (elas podem aprovar requerimentos ou atos do executivo, por exemplo). Nesse caso, a Câmara de SP aprovou uma lei que proíbe outdoors. A propósito, no que se refere ao uso de verbos em títulos, vale destacar que o Manual de Redação de O Estado de São Paulo (1998) sugere o emprego do presente do indicativo, em vez do pretérito, para que o título ganhe impacto e expressividade.

No caso em tela, o que se percebe é uma escala focal que conduz ou "faz transitar" a relevância ao constituinte menor à direita. Trata-se de um esqueleto em torno do qual a interpretação é construída. Observe-se:

(1a) A Câmara de SP fez algo.

(1b) O que fez a Câmara de SP?

(1c) A Câmara de SP aprovou algo.

(1d) O que a Câmara de SP aprovou?

(1e) A Câmara de SP aprovou a proibição de outdoor.

Se o escritor foi competente, ao final da tarefa, o leitor perceberá o constituinte menor sobre o qual se projeta a relevância: a polêmica da proibição de publicidade externa.

Qual seria então o papel dos demais elementos da chamada? Ao enunciado de título segue-se o enunciado que, segundo Caldeira (2007, p. 77), corresponde ao movimento/passo retórico de "Apontar um tema".

(2) A Câmara de São Paulo aprovou texto vetando a publicidade externa, como outdoors, faixas, banners e até anúncios em táxis e bicicletas.

O enunciado (2) é uma paráfrase do enunciado (1). Ele parece funcionar a rigor como uma explicitação narrativa da matéria. Como se destacou, o verbo que estava no presente do indicativo no título 'aprova', agora se reescreve no pretérito perfeito do indicativo (o tempo da narrativa em oposição ao tempo do comentário). Além disso, comparando o enunciado (2) com a descrição (1e), que apresenta em negrito as entradas lexicais usadas pelo enunciado (2), percebe-se que um conjunto de hipóteses lançado naquela interpretação é confirmado.

(2) A Câmara de São Paulo aprovou texto vetando a publicidade externa, como outdoors, faixas, banners e até anúncios em táxis e bicicletas.

(1e) ALGUM JORNALISTA DO JORNAL FOLHA DE S. PAULO AFIRMA NA CHAMADA DE CAPA DO JORNAL FOLHA DE S. PAULO QUE A CÂMARA DE VEREADORES DO MUNICÍPIO DE SÃo PAULO APROVA/APROVOU UMA LEI/TEXTO [DE LEI] DE PROIBIÇÃO DE /VETANDO OUTDOOR/ PUBLICIDADE EXTERNA, COMO OUTDOORS, FAIXAS, BANNERS E ATÉ ANÚNCIOS EM TÁXIS E BICICLETAS NO MUNICÍPIO DE SÃO PAULO NUM TEMPO QUE SUCEDE A APROVAÇÃO DA PROIBIÇÃO.

Observe-se que: o item lexical 'texto' permite a antecipação de que se trata de texto de algo e, portanto, texto de lei; o item lexical 'outdoor' é substituído pela sequência lexical 'publicidade externa', tecnicamente mais correta, embora menos enfática (tanto isso é verdade que o jornalista se vê na contingência de apresentar exemplos de publicidade externa "outdoors, faixas, banners e até anúncios em táxis e bicicletas"). 
Retomando-se a escala focal tem-se:

(1a) A Câmara de São Paulo fez algo.

(1b) O que fez a Câmara de São Paulo?

(1c) A Câmara de São Paulo aprovou algo.

(1d) O que a Câmara de São Paulo aprovou?

(1e) A Câmara de São Paulo aprovou um texto de lei vetando a publicidade externa, como outdoors, faixas, banners e até anúncios em táxis e bicicletas.

Seguem os enunciados que, segundo Caldeira, correspondem ao movimento de "especificar o tema" e ao passo de "listar fatos relacionados".

(3) O prefeito Gilberto Kassab (PFL), autor do projeto original, vai sancionar a lei.

(4) Os vereadores ampliaram as proibições, vetando anúncios em aviões, por exemplo.

(5) A Câmara estendeu para 31 de dezembro o prazo para retirada da propaganda existente, que era de 30 dias.

(6) Os vereadores também revogaram lei que permitia, por licitação, passar à iniciativa privada a venda de anúncios no mobiliário urbano.

(7) Kassab terá de enviar novo projeto sobre o assunto.

A rigor, o enunciado (3) destaca a autoria do projeto [de lei] original e aponta para a sanção da lei. O enunciado (4) destaca ampliações das proibições (a inferência é de que não se trata mais do texto original de Kassab), enfatizando a proibição de anúncios em aviões. Esses enunciados têm a ver estritamente com o tema da matéria e podem ser acoplados à escala focal. Veja-se.

(1f) algum jornalista do jornal folha de s. paulo afirma na chamada de capa do jornal folha de s. paulo que a câmara de vereadores do município de são paulo aprovou projeto ampliado de texto de lei do prefeito gilberto kassab (pfl) vetando publicidade externa, como outdoors, faixas, banners, anúncios em táxis e bicicletas e aviões no município de são paulo num tempo que sucede a aprovação da proibição.

Os enunciados (5-7) listam fatos relacionados. O enunciado (5) refere-se à ampliação do prazo para retirada da propaganda, mais uma vez endossando que o projeto original foi alterado. Os enunciados (6-7) destacam lei conexa à proibição "que permitia, por licitação, passar à iniciativa privada a venda de anúncios no mobiliário urbano”. Sobre esse assunto, Kassab tem de propor novo projeto [de lei]. Por hipótese, trata-se de assuntos derivados que remetem a um aprofundamento da matéria.

Por fim, ocorre a indexação do texto chamado, o caderno "C1". Caldeira assume que essa indexação corresponde ao movimento/passo IV de "direcionar a páginas internas do jornal”. Para Siqueira (2006), a indicação do caderno e do número da página interna onde está impressa a matéria completa, ou seja, a remissão para as páginas internas é o que de fato caracteriza a chamada como gênero.

Conhecidos os enunciados da chamada de capa, cabe agora perguntar que relações eles estabelecem com o texto chamado. Antes, contudo, há de se destacar que o texto chamado tem, ele próprio, um texto de chamada.

\section{ANÁLISE DA CHAMADA DE CAPA E DO TEXTO CHAMADO}

A primeira comparação a ser feita é entre a chamada de capa e o lead da própria matéria do texto chamado. Conforme o Manual de $O$ Globo (1997, p. 32), o lead ou guia, corresponde às primeiras linhas do texto de jornal que serve para conduzir e atrair o leitor como uma sedução. Trata-se dos enunciados introdutórios de 
uma notícia: quem fez o quê, como, onde, quando e por quê. Mais adiante o Manual destaca duas exigências: a de que o texto completo expresse o que foi anunciado pelo lead; e a de que sejam destinados espaços correspondentes para o que o lead anuncia como importante no texto completo.

Essa comparação pode ser vista no quadro a seguir:

\begin{tabular}{|c|c|}
\hline Texto da chamada de capa & Texto do lead do texto chamado \\
\hline $\begin{array}{l}\text { (1) Câmara de SP aprova proibição de } \\
\text { outdoor }\end{array}$ & (1) Câmara proíbe outdoors em São Paulo \\
\hline $\begin{array}{l}\text { (2) A Câmara de São Paulo aprovou texto } \\
\text { vetando a publicidade externa, como } \\
\text { outdoors, faixas, banners e até anúncios em } \\
\text { táxis e bicicletas. }\end{array}$ & $\begin{array}{l}\text { (2a) Nova lei também veta anúncios em } \\
\text { ônibus, táxis }[\ldots]\end{array}$ \\
\hline $\begin{array}{l}\text { (3) O prefeito Gilberto Kassab (PFL), autor } \\
\text { do projeto original, vai sancionar a lei. }\end{array}$ & \\
\hline $\begin{array}{l}\text { (4) Os vereadores ampliaram as proibições, } \\
\text { vetando anúncios em aviões, por exemplo. }\end{array}$ & (2b) $[\ldots]$ e até em aviões; \\
\hline $\begin{array}{l}\text { (5) A Câmara estendeu para } 31 \text { de dezembro } \\
\text { o prazo para retirada da propaganda } \\
\text { existente, que era de } 30 \text { dias. }\end{array}$ & $\begin{array}{l}\text { (2c) empresas têm até o fim do ano para } \\
\text { retirar a propaganda }\end{array}$ \\
\hline \multicolumn{2}{|l|}{$\begin{array}{l}\text { (6) Os vereadores também revogaram lei que } \\
\text { permitia, por licitação, passar à iniciativa } \\
\text { privada a venda de anúncios no mobiliário } \\
\text { urbano. }\end{array}$} \\
\hline \multicolumn{2}{|l|}{$\begin{array}{l}\text { (7) Kassab terá de enviar novo projeto sobre } \\
\text { o assunto. }\end{array}$} \\
\hline & $\begin{array}{l}\text { (3) Multa para quem desobedecer a norma } \\
\text { será de, no mínimo, R\$ } 10 \text { mil; prefeito } \\
\text { Kassab promete fiscalização "rigorosa" }\end{array}$ \\
\hline & $\begin{array}{l}\text { (4) EVANDRO SPINELLI } \\
\text { (5) JOSÉ ERNESTO CREDENDIO } \\
\text { (6) DA REPORTAGEM LOCAL }\end{array}$ \\
\hline (8) Pág. C1 & \\
\hline
\end{tabular}

Quadro 2 - Comparação do texto da chamada de capa com o lead do texto chamado da chamada de capa 27 coletada da edição de 27 de setembro de 2006 de Folha de S. Paulo por Caldeira (2007).

Fonte: elaboração própria.

O Manual de Redação e Estilo de O Estado de São Paulo (1998) sugere que o título utilizado na chamada de capa não deve ser rigorosamente semelhante ao da notícia no interior do jornal e isso é o que acontece quando se comparam os dois títulos. Consequentemente, a hipótese de que o título funciona como escala focal que direciona a relevância se repete no título do texto chamado. Veja-se:

(1) Câmara proíbe outdoors em São Paulo.

(1g) EVANDRO SPINELLI E JOSÉ CREDENDIO DA REPORTAGEM LOCAL DO JORNAL FOLHA DE S. PAULO AFIRMAM NO LEAD DO TEXTO DESENVOLVIDO DA CHAMADA DE CAPA DO JORNAL FOLHA DE S. PAULO QUE A CÂMARA DE VEREADORES DO MUNICÍPIO DE SÃO PAULO APROVOU PROJETO AMPLIADO DE TEXTO DE LEI DO PREFEITO GILBERTO KASSAB (PFL) PROIB(INDO)/VETANDO OUTDOORS/PUBLICIDADE EXTERNA, COMO OUTDOORS, FAIXAS, BANNERS, ANÚNCIOS EM TÁXIS E BICICLETAS E AVIÕES EM/NO MUNICÍPIO DE SÃO PAULO NUM TEMPO QUE SUCEDE A APROVAÇÃO DA PROIBIÇÃO.

Agora o item lexical 'São Paulo’ ocupa a posição lógica destinada à circunstância locativa. Por hipótese, por estar em um caderno local, a possibilidade de se interpretar que o item lexical 'câmara' se refira a outra câmara de vereadores que não a paulistana é muito pequena para exigir a determinação. A construção "aprova a proibição de outdoor" é parafraseada por "proíbe outdoors". Ambas as construções estão no presente do indicativo e mantêm os mesmos efeitos já destacados na seção anterior. 
O segundo enunciado do lead corresponde aos enunciados (2), (4) e (5) do texto da chamada de capa. Nesse enunciado, antes do ponto e vírgula, a proibição é qualificada como "Nova lei". O conceito de publicidade externa é omitido, supostamente por ser tautológico. Os jornalistas explicitam no texto a proibição de anúncios em "ônibus (informação nova), táxis (enunciado 2) e até em aviões (enunciado 4)". O item lexical 'até' emerge supostamente por essa proibição ter sido um acréscimo da Câmara de Vereadores ao projeto original do prefeito Gilberto Kassab. Em seguida ao ponto e vírgula, destaca-se novamente o prazo para a retirada das propagandas (enunciado 5), informação essa que não pode ser subsumida pela escala focal.

(2) Nova lei também veta anúncios em ônibus, táxis e até em aviões; [...].

(1h) EVANDRO SPINELLI E JOSÉ CREDENDIO DA REPORTAGEM LOCAL DO JORNAL FOLHA DE S. PAULO AFIRMAM NO LEAD DO TEXTO DESENVOLVIDO DA CHAMADA DE CAPA DO JORNAL FOLHA DE S. PAULO QUE A CÂMARA DE VEREADORES DO MUNICÍPIO DE SÃO PAULO APROVOU NOVA LEI/PROJETO AMPLIADO DE TEXTO DE LEI DO PREFEITO GILBERTO KASSAB (PFL) VETA(NDO) PUBLICIDADE EXTERNA, COMO OUTDOORS, FAIXAS, BANNERS, ANÚNCIOS EM ÔNIBUS, TÁXIS E BICICLETAS E ATÉ AVIÕES NO MUNICÍPIO DE SÃO PAULO NUM TEMPO QUE SUCEDE A APROVAÇÃO DA PROIBIÇÃO.

Perceba-se que não há uma retomada dos enunciados (6) e (7) do texto da chamada de capa no lead. Por outro lado, o lead destaca duas informações novas: a de que o valor da multa é de 10 mil reais e a de que o prefeito promete fiscalização "rigorosa". Essas diferenças sugerem que a chamada de capa e o lead mapeiam as informações do texto completo de modo diferente: a primeira destacando a questão das licitações e o segundo a questão da multa e da fiscalização.

Por fim, vale mencionar que, entre o lead e o texto desenvolvido, apresentam-se as credenciais da matéria, atribuída a Evandro Spinelli e José Ernesto Credendio da reportagem local de Folha de S. Paulo. Além disso, obviamente, a indexação da página na chamada de capa cumpre-se pelo número da página onde se encontra o lead e a matéria.

Com base nesse primeiro cotejo, pode-se comparar no quadro 3 o texto da chamada de capa, acrescido das informações do lead em itálico na primeira coluna, com a matéria completa na segunda coluna. A ordem dos números dos enunciados do texto chamado é uma função das correspondências com o texto da chamada de capa.

\begin{tabular}{|c|c|}
\hline $\begin{array}{l}\text { Texto da chamada de capa acrescido do } \\
\text { texto do lead em itálico }\end{array}$ & Texto chamado \\
\hline $\begin{array}{l}\text { (2) A Câmara de São Paulo aprovou texto } \\
\text { vetando a publicidade externa, como } \\
\text { outdoors, faixas, banners e até anúncios em } \\
\text { ônibus, táxis e bicicletas. } \\
\text { (2a) Nova lei também veta anúncios em ônibus, } \\
\text { táxis […] } \\
\text { (3) O prefeito Gilberto Kassab (PFL), autor } \\
\text { do projeto original, [...]. }\end{array}$ & $\begin{array}{l}\text { (7) A Câmara de São Paulo aprovou ontem uma lei } \\
\text { que acaba com a propaganda externa na cidade. } \\
\text { (8) A partir de } 1^{\circ} \text { de janeiro ficam proibidos painéis } \\
\text { eletrônicos, outdoors, faixas e banners. } \\
\text { (9) Todo comércio e serviços, incluindo bancos, } \\
\text { terá que reduzir as placas nas fachadas. } \\
\text { (16a) Além da propaganda em placas, também } \\
\text { estarão proibidas a publicidade em táxis, a } \\
\text { distribuição de panfletos em vias públicas [...] } \\
\text { (14a) [...], Kassab obteve uma vitória expressiva - } \\
\text { foram } 45 \text { votos a } 1 \text {. }\end{array}$ \\
\hline $\begin{array}{l}\text { (3) O prefeito Gilberto Kassab (PFL) }[\ldots . .] \text { vai } \\
\text { sancionar a lei. }\end{array}$ & $\begin{array}{l}\text { (10) O prefeito Gilberto Kassab (PFL) sancionou } \\
\text { ontem mesmo o projeto. } \\
\text { (15) “Em pouco tempo, poderemos sonhar com uma } \\
\text { diminuição radical da poluição visual”, declarou o } \\
\text { prefeito. } \\
\text { (20) O texto original, de autoria do prefeito [...]. }\end{array}$ \\
\hline $\begin{array}{l}\text { (4) Os vereadores ampliaram as proibições, } \\
\text { vetando anúncios em aviões, por exemplo. } \\
\text { (2b) [...] e até em aviões; }\end{array}$ & $\begin{array}{l}\text { (16b) [...] e até a veiculação de anúncios em } \\
\text { dirigíveis e aviões. } \\
\text { (20) [...] foi alterado por um acordo entre os } \\
\text { líderes dos partidos e ficou ainda mais restritivo. } \\
\text { (21) Diminuiu, por exemplo, o tamanho máximo de } \\
\text { placas em fachadas de até } 10 m \text { - que passou de }\end{array}$ \\
\hline
\end{tabular}




\begin{tabular}{|c|c|}
\hline & $4 \mathrm{~m} 2$ para $1,5 \mathrm{~m} 2$ \\
\hline $\begin{array}{l}\text { (5) A Câmara estendeu para } 31 \text { de dezembro } \\
\text { o prazo para retirada da propaganda } \\
\text { existente, que era de } 30 \text { dias. } \\
\text { (2c) empresas têm até o fim do ano para retirar a } \\
\text { propaganda }\end{array}$ & $\begin{array}{l}\text { (22) Por outro lado, o projeto de Kassab previa } \\
\text { somente } 30 \text { dias para a lei entrar em vigor, prazo } \\
\text { estendido para até o fim do ano, e ainda permite } \\
\text { que a prefeitura conceda mais } 90 \text { dias, caso o } \\
\text { proprietário do anúncio prove que não conseguiu } \\
\text { retirá-lo por algum motivo. }\end{array}$ \\
\hline $\begin{array}{l}\text { (6) Os vereadores também revogaram lei que } \\
\text { permitia, por licitação, passar à iniciativa } \\
\text { privada a venda de anúncios no mobiliário } \\
\text { urbano. }\end{array}$ & $\begin{array}{l}\text { (23) Na mesma sessão, os vereadores revogaram } \\
\text { uma outra lei que permitia à prefeitura licitar a } \\
\text { propaganda no mobiliário urbano. } \\
\text { (17) O que continuará valendo provisoriamente em } \\
\text { 2007, mas apenas até o vencimento dos contratos, } \\
\text { serão as propagandas em ônibus e no mobiliário } \\
\text { urbano (bancas, pontos de ônibus, lixeiras, relógios } \\
\text { etc.). }\end{array}$ \\
\hline $\begin{array}{l}\text { (7) Kassab terá de enviar novo projeto sobre } \\
\text { o assunto. }\end{array}$ & $\begin{array}{l}\text { (24) Kassab terá que enviar novo projeto e negociar } \\
\text { para conseguir privatizar a exploração do espaço } \\
\text { público }\end{array}$ \\
\hline $\begin{array}{l}\text { (3) Multa para quem desobedecer a norma será } \\
\text { de, no mínimo, } R \$ 10 \text { mil; prefeito Kassab } \\
\text { promete fiscalização "rigorosa" }\end{array}$ & $\begin{array}{l}\text { (11) “A lei foi aprovada para valer, e a fiscalização } \\
\text { será mais rigorosa ainda”, disse. } \\
\text { (12) Segundo ele, serão criadas equipes especiais } \\
\text { para retirar anúncios irregulares. } \\
\text { (13) A multa mínima para quem descumprir a lei } \\
\text { será de } \mathrm{R} \$ 10 \text { mil. }\end{array}$ \\
\hline & $\begin{array}{l}\text { (14a) Mesmo sob protestos e contra o lobby das } \\
\text { empresas de publicidade exterior, setor que } \\
\text { movimenta R\$ } 200 \text { milhões ao ano na cidade, [...]. } \\
\text { (18) O mercado publicitário reagiu, fala em ameaça } \\
\text { a cerca de } 20 \text { mil empregos e já preparou pareceres } \\
\text { jurídicos para entrar na Justiça contra a prefeitura. } \\
\text { (19) A Associação Comercial de São Paulo } \\
\text { considera a lei de difícil aplicação e também prevê } \\
\text { uma corrida à Justiça. } \\
\text { (25) O único voto contrário ao projeto foi do } \\
\text { vereador Dalton Silvano (PSDB), ligado à área de } \\
\text { publicidade. } \\
\text { (26) "Quem perdeu foi a cidade de São Paulo. } \\
\text { (27) Uma cidade sem publicidade é uma cidade } \\
\text { fria", disse. }\end{array}$ \\
\hline
\end{tabular}

Quadro 3 - Comparação do tex to da chamada de capa acrescido do tex to do lead do texto chamado com o tex to desenvolvido da chamada de capa 27 coletada da edição de 27 de setembro de 2006 de Folha de $S$.

Paulo por Caldeira (2007).

Fonte: Elaboração própria.

Cotejando os textos, é possível detectar que a chamada de capa e o lead compartilham com o texto chamado uma série de características. O enunciado (7) do texto chamado é uma paráfrase do enunciado (2) da chamada de capa, cabendo aos enunciados (8), (9), (14a) e (16a) conformarem-se como detalhamentos. A sequência lexical 'publicidade externa', parafraseada por 'propaganda externa', funciona como hiperônimo das possibilidades de anúncios. O texto chamado acrescenta o prazo de início da aplicação da lei e a redução de placas nas fachadas.

(1i) evandro spinelli e josé credendio da reportagem local do jornal folha de s. paulo afirmam no texto desenvolvido da chamada de capa do jornal folha de s. paulo que a câmara de vereadores do município de são paulo aprovou por 45 votos a 1 , no dia 26 de setembro de 2006, uma lei que provém de projeto ampliado de texto de lei do prefeito gilberto kassab (pfl) acaba(ndo) com a propaganda/publicidade externa, como painéis eletrônicos, placas nas fachadas, outdoors, faixas, banners, publicidade em ônibus, táxis e bicicletas e até aviões e distribuição de panfletos em vias públicas no município de são paulo a partir de $1^{\circ}$ de janeiro de $2007 /$ num tempo que sucede a aprovação da proibição. 
O enunciado (4) da chamada é retomado pelos enunciados (16b), (20) e (21) do texto chamado. Mais uma vez, o veto de anúncios em aviões, destacado no lead, é posto em destaque e atribuído aos vereadores. O texto chamado acrescenta ter havido "um acordo entre os líderes dos partidos" e retoma a ideia de o projeto ter ficado "mais restritivo". O enunciado (21) do texto chamado ilustra essas restrições, dando detalhes das medidas das placas em fachadas. Esse enunciado não se conecta com algum enunciado da chamada de capa, mas com o enunciado (9) do próprio texto chamado.

(1j) evandro spinelli e josé credendio da reportagem local do jornal folha de s. paulo afirmam no texto desenvolvido da chamada de capa do jornal folha de s. paulo que a câmara de vereadores do município de são paulo aprovou por 45 votos a 1, no dia 26 de setembro de 2006, uma lei que provém de projeto ampliado e mais restritivo negociado por um acordo entre os líderes dos partidos do texto de lei do prefeito gilberto kassab (pfl) acaba(ndo) com a publicidade externa, como painéis eletrônicos, placas nas fachadas, outdoors, faixas, banners, anúncios em ônibus, táxis e bicicletas e até dirigíveis e aviões e distribuição de panfletos em vias públicas no município de são paulo a partir de $1^{\circ}$ de janeiro de 2007.

O enunciado (3) da chamada é retomado nos enunciados (10) e (20) do texto chamado. Todavia produz-se uma incongruência. Na chamada, o jornal anuncia que o prefeito "vai sancionar a lei", quando no texto chamado afirma que "sancionou ontem mesmo o projeto". A autoria da lei é atribuída ao prefeito Gilberto Kassab no enunciado (20) do texto chamado, e há pistas de que a aprovação do projeto é do prefeito nos enunciados (14b) e (15).

A questão dos prazos, objeto do enunciado (5) da chamada de capa e (2c) do lead, é desenvolvida pelo enunciado (22) do texto chamado. Acrescenta-se no texto chamado a informação de concessões adicionais de prazo para casos fundamentados.

A questão das licitações sobre o espaço público, destacada no enunciado (6) da chamada de capa e omitida no lead, é retomada no enunciado (23) do texto chamado. O enunciado (17) acrescenta que contratos de licitação assinados anteriormente serão respeitados. Destaque-se, no entanto, que essa informação está apresentada logo em seguida das proibições aprovadas pela câmara nos enunciados (7-16). Já a necessidade de novo projeto, destacada no enunciado (7) da chamada, é ampliada no enunciado (24) do texto chamado. O item lexical 'assunto' refere-se à "licitação de propaganda no mobiliário urbano". O enunciado (24) acrescenta a ideia de que essa questão requer negociação.

A questão da multa e da fiscalização exposta no enunciado (3) do lead, mas não considerada na chamada, é desenvolvida nos enunciados (11-13) do texto chamado. O enunciado (12) acrescenta a ideia da criação de "equipes especiais para retirar anúncios irregulares".

Destaque-se, ainda, que seis enunciados do texto chamado não foram antecipados nem na chamada nem no lead. Todos eles se referem às opiniões divergentes derrotadas na votação. Trata-se de protestos e "lobby das empresas de publicidade exterior" (14a), ameaça de desemprego (18) e corrida à justiça (18) e (19). No fim do texto chamado, nos enunciados (25-27), dá-se voz ao único voto divergente de Dalton Silvano (PSDB), considerado "ligado à área de publicidade".

\section{CONSIDERAÇÕES FINAIS}

Os gêneros textuais são estruturas relativamente estabilizadas de modos de dizer, que configuram ações sociais e são por elas configurados. Por hipótese, parte dessa estabilização decorre de arranjos sintáticos que, do ponto de vista pragmático-cognitivo aumentam efeitos cognitivos e diminuem esforços de processamento. No nível sentencial, produzir enunciados em que cada constituinte sintático implica analiticamente o constituinte anterior e é implicado analiticamente pelo constituinte seguinte forma uma escala focal que cumpre a função de diminuir o esforço de processamento. Da mesma forma, se forem consideradas as relações que se estabelecem entre a chamada de capa e o texto da matéria ou entre a chamada de capa, o lead e a matéria, pode-se perceber que esses textos guardam entre si certa relação focal.

Tendo analisado a chamada de capa e o texto desenvolvido sobre a proibição de publicidade externa em São Paulo, percebeu-se um conjunto de evidências que, de forma preliminar, podem revelar esse tipo de fenômeno. No que se refere aos títulos, enunciados enfatizados nesse artigo, percebeu-se que eles mapeiam o 
tema da matéria de forma praticamente semelhante. De fato, o constituinte sintático em foco é 'outdoor', como item lexical que se alarga semanticamente para ocupar a ideia de publicidade externa.

Em seguida, chamada e lead mapeiam de modo ligeiramente diferente os elementos mais destacados da matéria. Os enunciados que seguem os títulos funcionam como explicitação narrativa da matéria anunciada pelo título. No lead, contudo, elementos sobre os locais e da proibição dos enunciados (4) e (5) da chamada compõem esse segundo enunciado. Todas essas informações são desenvolvidas no texto chamado. A informação sobre a sanção é discrepante no texto da chamada e no texto desenvolvido. Dados sobre a licitação de espaços públicos não são destacados no lead e dados sobre multa e físcalização não são destacados na chamada. Todavia, ambos os dados são desenvolvidos no texto. Somente dados relativos a posições divergentes são omitidas nos textos de chamada e de lead.

Diante desse conjunto de dados, uma série de questionamentos pode ser desenvolvida em pesquisas futuras. A função de escala focal é similar em títulos de chamadas de capa e de texto chamado? Chamadas de capa constituídas apenas de títulos cumprem essa função da mesma forma? O primeiro enunciado de desenvolvimento da chamada funciona como desenvolvimento narrativo da forma lógica do título ao modo de um lead? Os enunciados que seguem o título da chamada de capa constituem-se destaques intencionais de tópicos? Nesse caso, os enunciados do lead mapeiam tópicos de modo diferente dos enunciados da chamada de capa? O mapeamento das formas proposicionais dos enunciados da chamada e do lead encontra que espécie de correspondência com as formas proposicionais dos enunciados dos textos chamados?

Considerando-se esse estudo exploratório inicial, é possível argumentar que se a dimensão relevante da chamada de capa é a proibição de publicidade externa e suas consequências para a vida dos paulistanos, o título e os itens destacados da chamada e do lead foram estruturados para destacá-las. Por hipótese, essa estratégia reduz o custo de processamento desses detalhamentos e, especialmente para quem estava envolvido na questão, supostamente motivou a leitura dos elementos publicados na matéria desenvolvida.

\section{REFERÊNCIAS}

BHATIA, V. K. Analysing genre: language use in professional settings. New York: Longman, 1993.

BIBER, D. Variation across speech and writing. New York: Cambridge University Press, 1988.

BONINI, A. Os gêneros do jornal: o que aponta a literatura da área de comunicação no Brasil. Linguagem em (Dis)curso, v. 4, n.1, jul./dez., 2003a.

Veículo de comunicação e gênero textual: noções conflitantes. DELTA, v.19, n.1, 2003b. Disponível em: <http://www.scielo.br/scielo.php?script=sci_arttext\&pid=S0102-44502003000100003> Acesso em: 19 jun. 2011.

Em busca de um modelo integrado para os gêneros do jornal. In: CAVALCANTE, M. M; BRITO, M. A. P. (Orgs.). Gêneros textuais e referenciação. Fortaleza, CE: PPGL/UFC, 2004.

CALDEIRA, A. B. Chamada de capa: análise do gênero jornalístico com abordagem sócio-retórica de Swales, 2007. Dissertação (Mestrado em Ciências da Linguagem) - Programa de Pós-graduação em Ciências da Linguagem, Universidade do Sul de Santa Catarina, 2007.

ERBOLATO, M. L. Técnicas de codificação em jornalismo: redação, captação e edição no jornal diário. 5. ed. São Paulo: Ática, 1991.

FERREIRA JÚNIOR, J. Capas de jornal: a primeira imagem e o espaço gráfico visual. São Paulo: Ed. Senac, 2003.

FOLHA DE S. PAULO. Manual geral da redação. 2. ed. São Paulo: Folha de São Paulo, 1987.

MARTINS, E. Manual de redação e estilo: O Estado de São Paulo. 3. ed. São Paulo: Moderna, 1998.

MELO, J. M. de. A opinião no jornalismo brasileiro. 2. ed. Petrópolis: Vozes, 1994.

O GLOBO; GARCIA, L. Manual de redação e estilo. 24. ed. São Paulo: Globo, 1997.

RAUEN, F. J. Teoria da relevância e análise sociorretórica de gêneros textuais: análise das correlações entre chamadas de capa e textos chamados. In: SIMPÓSIO INTERNACIONAL DE ESTUDOS DE 
GÊNEROS TEXTUAIS, 6., 2011, Natal. Anais... Natal: Ed. da UFRN, 2011. p. 1 - 17. Disponível em: $<$ http://www.cchla.ufrn.br/visiget/pgs/pt/anais/Artigos/Fábio\%20José\%20Rauen\%20(UNISUL).pdf>. Acesso em: 1 mar. 2012.

Teoria da relevância e análise sócio-retórica de gêneros textuais: análise de respostas em cartasconsulta diretas e indiretas. Revista Signos [on line], v. 43, p. 205-225, 2010.

. Relevance and genre: theoretical and conceptual interfaces. In: BAZERMAN, C.; BONINI, A.; FIGUEIREDO, D. (Orgs.). Genre in a changing world. 1. ed. Fort Collins, Colorado, EUA: WAC Clearinghouse and Parlor Press, 2009. v. 1, p. 57-77.

Teoria da relevância e gêneros textuais: interfaces possíveis. In: SIMPÓSIO INTERNACIONAL DE ESTUDOS DE GÊNEROS TEXTUAIS/ INTERNATIONAL SYMPOSIUM ON GENRE STUDIES, 4., 2007, Tubarão, SC. Anais... Tubarão: Universidade do Sul de Santa Catarina, 2007. v. 1, p. 1012-1022.

SIQUEIRA, A. B. A importância da primeira página. Disponível em: $<$ http://www.usc.br/analisedemidia/Downloads/fichaati.pdf> Acesso em: 20 jul. 2006.

SPERBER, D; WILSON, D. Relevance: communication \& cognition. 2nd. ed. Oxford: Blackwell, 1995 [1st. ed. 1986].

SWALES, J. M. Genre analysis: English in academic and research settings. New York: Cambridge U. P., 1990.

Recebido em 07/03/12. Aprovado em 10/05/12. 